\title{
Chemotherapy is not necessary for early- stage serous and endometrioid ovarian cancer after undergoing comprehensive staging surgery
}

\author{
Shuqing Li and Zhiling Zhu*
}

\begin{abstract}
In order to investigate whether adjuvant chemotherapy is essential for patients with early-stage serous and endometrioid epithelial ovarian cancer, the present study collected data from the US Surveillance, Epidemiology and End Results database between 2004 and 2015. All subjects underwent comprehensive staging surgery and were diagnosed as stages IA-IIA, grade 1-2. A total of 2644 patients were enrolled in the present study, among which 1589 patients received platinum-based chemotherapy. Comparisons of categorical data were performed via $X^{2}$ tests. Variables with $P<0.05$ in univariate analyses were further analyzed using multiple logistic regression. Selection bias from the heterogeneity of demographic and clinical characteristics was avoided using propensity score matching. Cox proportional hazards models were applied to estimate hazard ratios (HRs) and 95\% confidence intervals (Cls), investigating the association between variables and 5-year overall survival. After the propensity score matching, there was an equal number of patients with or without chemotherapy $(n=925)$. The results of the present study indicated that those aged $\geq 65$ years were at an increased risk of ovarian cancer, and the age was associated with poor prognosis (HR, 1.486; Cl, 1.208-1.827; $P<0.001)$. Endometrioid carcinoma was associated with improved 5-year overall survival compared with serous cystadenocarcinoma ( $\mathrm{HR}, 0.697 ; \mathrm{Cl}, 0.584-0.833 ; P<0.001)$. Chemotherapy could not prolong the 5 -year overall survival of patients with early-stage serous and endometrioid ovarian cancer ( $\mathrm{HR}, 1.092 ; \mathrm{Cl}, 0.954-1.249 ; P=0.201)$. These results demonstrated that adjuvant chemotherapy was unnecessary for patients with early-stage serous and endometrioid ovarian cancer after they underwent comprehensive staging surgery.
\end{abstract}

Keywords: Ovarian cancer, Serous, Endometrioid, Chemotherapy, Overall survival

\section{Introduction}

Ovarian cancer is the leading cause of cancer-associated mortality among patients with gynecological malignancies worldwide. Data from the Surveillance, Epidemiology and End Results (SEER) database indicate that distant stage epithelial ovarian cancer (EOC) accounts for $59 \%$, regional stage for $20 \%$, and localized stage for

\footnotetext{
* Correspondence: 13211290014@fudan.edu.cn

Department of Obstetrics and Gynecology, Obstetrics and Gynecology Hospital of Fudan University, 128 Shenyang Road, Shanghai 200090, China
}

$15 \%$ of cases. A great majority of patients with advanced epithelial ovarian cancer undergo surgery and receive platinum-based chemotherapy, which has been recommended by National Comprehensive Cancer Network $(\mathrm{NCCN})$ guidelines [1-3]. However, whether adjuvant chemotherapy should be used for patients with earlystage ovarian cancer after they have received surgery remains controversial. The 5-year recurrence rate for early-stage ovarian cancer is currently $15-25 \%$ [4-6].

(c) The Author(s). 2020 Open Access This article is licensed under a Creative Commons Attribution 4.0 International License, which permits use, sharing, adaptation, distribution and reproduction in any medium or format, as long as you give appropriate credit to the original author(s) and the source, provide a link to the Creative Commons licence, and indicate if changes were made. The images or other third party material in this article are included in the article's Creative Commons licence, unless indicated otherwise in a credit line to the material. If material is not included in the article's Creative Commons licence and your intended use is not permitted by statutory regulation or exceeds the permitted use, you will need to obtain permission directly from the copyright holder. To view a copy of this licence, visit http://creativecommons.org/licenses/by/4.0/ The Creative Commons Public Domain Dedication waiver (http://creativecommons.org/publicdomain/zero/1.0/) applies to the data made available in this article, unless otherwise stated in a credit line to the data. 
The paclitaxel/carboplatin regimen has formed the cornerstone of chemotherapy in epithelial ovarian cancer over the past two decades, and has achieved a successful clinical response [7, 8]. Nevertheless, both agents have considerable side effects, ranging from anticipated myelosuppression, alopecia and gastrointestinal symptoms, to occasional severe neurotoxicity $[9,10]$. Notably, patients gradually develop chemoresistance with diminishing benefit from subsequent regimens [11-14]. Therefore, avoiding unnecessary chemotherapy will decrease the risk of drug resistance, increase the chance of secondary surgery and effectively prolong the 5 -year survival time of patients with early-stage disease. This relieves the psychological pressure and economic burden, and significantly improves the quality of life of the patients. Taking these needs into account, there is an urgent requirement to improve the current understanding of the significance of chemotherapy for patients with early-stage disease, and to provide more current information for clinical practice.

Serous cystadenocarcinoma and endometrioid carcinoma, which are the two most frequent subtypes of epithelial ovarian cancer, were investigated in the present study [15]. The study cohort was designed to enroll patients with stage IA-IIA, grade 1-2 serous and endometrioid ovarian cancer. They all received comprehensive staging surgery and were actively followed-up. Patients were divided into chemotherapy and nonchemotherapy groups. The chemotherapy groups received paclitaxel/carboplatin regimen every 3 weeks for $3-6$ cycles. The present study aimed to identify the necessity of adjuvant chemotherapy in early-stage serous and endometrioid ovarian cancer, which may provide a reference for gynecological oncologists.

\section{Methods}

\section{Data source}

The data in the present study were extracted from the US SEER database maintained by the National Cancer Institute. SEER*Stat software, version 8.3.5 was downloaded from the official website (https://seer.cancer.gov/). This program collects data from population-based cancer registries that currently cover $\sim 28 \%$ of the US population.

\section{Patient eligibility criteria}

The study design and inclusion criteria are detailed in the aforementioned paragraph. A total of 2644 patients participated in the present study (Fig. 1). The following

Patients diagnosed with primary ovarian cancer
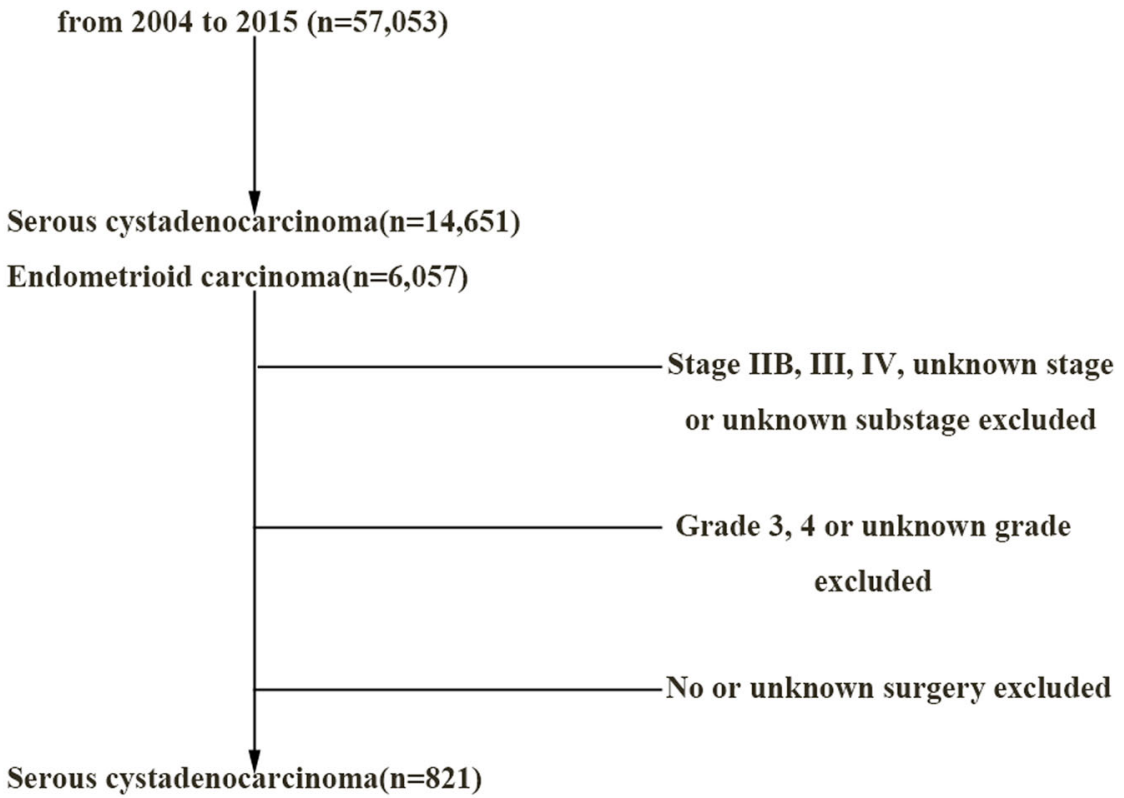

Endometrioid carcinoma(n=1,823)

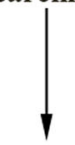

Study cohort $n=2,644$

Fig. 1 Consort diagram of patient selection 
clinical characteristics were included: Patient ID, age at diagnosis, race, survival months, tumor stage, tumor grade, tumor laterality, tumor size, surgery of primary site, type of surgery, chemotherapy, vital status, causespecific death classification, type of follow-up expected. Age at diagnosis was divided into three groups: $<45$, $45-65$ and $>65$ years. Race was classified into white and non-white. Tumor laterality whereby the tumor originated was grouped into right, left and other/unknown. Tumor size was categorized into three groups: $\leq 10 \mathrm{~cm}$, $>10 \mathrm{~cm}$ and unknown. Administration of chemotherapy fell into yes and no/unknown in the extracted dataset. The association between chemotherapy and 5-year overall survival (OS) was analyzed in all patients.

\section{Statistical analysis}

\section{Univariate analysis}

There were no cases with missing data. Pearson $\chi^{2}$ tests were used to evaluate univariate associations between categorical variables and chemotherapy before and after the propensity score matching. All tests were two-sided. $P<$ 0.05 was considered to indicate a statistically significant difference. Statistical analyses were performed using $\mathrm{R}$ software, version 3.5.1 and SPSS software, version 25.0.0.1.

\section{Propensity score matching}

Selection bias generally existed in retrospective studies due to the demographic heterogeneity and clinical characteristics between chemotherapy and non-chemotherapy groups. To lessen the influence of selection bias in the conclusions of the present study, propensity score matching was performed. A logistic regression model was applied to match age at diagnosis, race, tumor stage, tumor grade, tumor laterality, tumor size and histology between the two study groups. The propensity score ranged from 0 to 1 . The present study adopted the nearest neighbor matching and 1:1 match ratio in this model.

\section{Survival analysis}

The survival analysis was performed using the KaplanMeier method, and differences were compared via logrank tests. The present study performed cox proportional hazards models to estimate hazard ratios (HRs) and $95 \%$ confidence intervals (CIs).

\section{Results}

\section{Patient demographics}

The study inclusion criteria were met by 2644 eligible patients (1055 non-chemotherapy and 1589 chemotherapy). In this population, only $16.4 \%$ were aged < 45 years, $56.1 \%$ were aged $45-65$ years, and $27.5 \%$ were aged $\geq 65$ years. A large majority of patients were white $(n=2243 ; 84.8 \%)$. Stage IA accounted for $44.2 \%$, stage IB for $5.7 \%$, stage IC for $38.4 \%$, and stage
IIA for $11.7 \%$. Of the 2644 patients, $59.1 \%$ were diagnosed with grade 1 , and $40.9 \%$ with grade 2 . Tumor laterality consisted of right ( $n=1112 ; 42.1 \%)$, left $(n=$ $1121 ; 42.4 \%)$ and other/unknown ( $n=411 ; 15.5 \%)$. There were $44.3 \%$ of patients who had tumors $<10$ $\mathrm{cm}$ in size, and $42.3 \%$ with tumors $>10 \mathrm{~cm}$. In the present study, endometrioid carcinoma accounted for $68.9 \%$, and serous cystadenocarcinoma for $31.1 \%$ of cases. Patients characteristics are presented in Table 1.

\section{Comparison of univariate covariates}

Before the propensity score matching, patients in the chemotherapy groups tended to be younger than those in the non-chemotherapy groups ( $\leq 45$ years:

Table 1 Patient demographics

\begin{tabular}{|c|c|c|}
\hline Characteristics & Number of patients & $\%$ \\
\hline \multicolumn{3}{|l|}{ Chemotherapy } \\
\hline No/Unknown & 1055 & 39.9 \\
\hline Yes & 1589 & 60.1 \\
\hline \multicolumn{3}{|l|}{ Age, years } \\
\hline$\leq 45$ & 434 & 16.4 \\
\hline $45-65$ & 1484 & 56.1 \\
\hline$>65$ & 726 & 27.5 \\
\hline \multicolumn{3}{|l|}{ Race } \\
\hline White & 2243 & 84.8 \\
\hline Non-white & 401 & 15.2 \\
\hline \multicolumn{3}{|l|}{ Stage } \\
\hline IA & 1170 & 44.2 \\
\hline $\mathrm{IB}$ & 152 & 5.7 \\
\hline IC & 1014 & 38.4 \\
\hline$\| \mathrm{A}$ & 308 & 11.7 \\
\hline \multicolumn{3}{|l|}{ Grade } \\
\hline 1 & 1562 & 59.1 \\
\hline 2 & 1082 & 40.9 \\
\hline \multicolumn{3}{|l|}{ Laterality } \\
\hline Right & 1112 & 42.1 \\
\hline Left & 1121 & 42.4 \\
\hline Other/Unknown & 411 & 15.5 \\
\hline \multicolumn{3}{|l|}{ Tumor size, cm } \\
\hline$\leq 10$ & 1171 & 44.3 \\
\hline$>10$ & 1119 & 42.3 \\
\hline Unknown & 354 & 13.4 \\
\hline \multicolumn{3}{|l|}{ Histology } \\
\hline Serous & 821 & 31.1 \\
\hline Endometrioid & 1823 & 68.9 \\
\hline
\end{tabular}


Table 2 Comparison of univariate covariates

\begin{tabular}{|c|c|c|c|c|c|c|}
\hline \multirow[b]{2}{*}{ Characteristics } & \multirow[b]{2}{*}{$\begin{array}{l}\text { Chemotherapy- } \\
(n=1055)\end{array}$} & \multirow{2}{*}{$\begin{array}{l}\text { Before PSM } \\
\text { Chemotherapy+ } \\
(n=1589)\end{array}$} & \multirow[t]{2}{*}{$P$-value } & \multirow[b]{2}{*}{$\begin{array}{l}\text { Chemotherapy- } \\
(n=925)\end{array}$} & \multirow{2}{*}{$\begin{array}{l}\text { After PSM } \\
\text { Chemotherapy+ } \\
(n=925)\end{array}$} & \multirow{2}{*}{$\begin{array}{l}\text { P- } \\
\text { value }\end{array}$} \\
\hline & & & & & & \\
\hline Age & & & $<0.001$ & & & 0.254 \\
\hline$\leq 45$ & $161(15.3)$ & $273(17.2)$ & & $159(17.2)$ & $183(19.8)$ & \\
\hline $45-65$ & $538(51.0)$ & $946(59.5)$ & & $504(54.5)$ & $503(54.4)$ & \\
\hline$>65$ & 356 (33.7) & $370(23.3)$ & & $262(28.3)$ & $239(25.8)$ & \\
\hline Race & & & 0.086 & & & 0.124 \\
\hline White & $911(86.4)$ & 1332 (83.8) & & $793(85.7)$ & $768(83.0)$ & \\
\hline Non-white & 144 (13.6) & $257(16.2)$ & & $132(14.3)$ & $157(17.0)$ & \\
\hline Stage & & & $<0.001$ & & & 0.328 \\
\hline IA & $626(59.3)$ & $544(34.2)$ & & 499 (53.9) & $475(51.4)$ & \\
\hline IB & $60(5.7)$ & $92(5.8)$ & & $57(6.2)$ & $49(5.3)$ & \\
\hline IC & $283(26.8)$ & $731(46.0)$ & & $283(30.6)$ & 319 (34.5) & \\
\hline$\| \mathrm{A}$ & $86(8.2)$ & $222(14.0)$ & & $86(9.3)$ & $82(8.9)$ & \\
\hline Grade & & & $<0.001$ & & & 0.530 \\
\hline 1 & $721(68.3)$ & $841(52.9)$ & & $595(64.3)$ & $581(62.8)$ & \\
\hline 2 & $334(31.7)$ & $748(47.1)$ & & $330(35.7)$ & $344(37.2)$ & \\
\hline Laterality & & & $<0.001$ & & & 0.147 \\
\hline Right & $477(45.2)$ & $635(40.0)$ & & $407(44.0)$ & $383(41.4)$ & \\
\hline Left & $461(43.7)$ & $660(41.5)$ & & 405 (43.8) & $401(43.4)$ & \\
\hline Other/Unknown & $117(11.1)$ & $294(18.5)$ & & $113(12.2)$ & $141(15.2)$ & \\
\hline Tumor size, cm & & & 0.044 & & & 0.888 \\
\hline$\leq 10$ & $464(44.0)$ & $707(44.5)$ & & $414(44.8)$ & $416(45.0)$ & \\
\hline$>10$ & $429(40.7)$ & $690(43.4)$ & & $386(41.7)$ & $391(42.3)$ & \\
\hline Unknown & $162(15.4)$ & $192(12.1)$ & & $125(13.5)$ & $118(12.8)$ & \\
\hline Histology & & & 0.001 & & & 0.226 \\
\hline Serous & $289(27.4)$ & $532(33.5)$ & & $257(27.8)$ & $233(25.2)$ & \\
\hline Endometrioid & 766 (72.6) & $1057(66.5)$ & & $668(72.2)$ & $692(74.8)$ & \\
\hline
\end{tabular}

Data are expressed as $\mathrm{n}(\%) . P<0.05$ was considered to indicate a statistically significant difference. PSM propensity score matching

17.2 vs. $15.3 \%$; $45-65$ years: 59.5 vs. $51.0 \% ; P<0.001)$. They were less likely to be in stage IA (34.2 vs. $59.3 \% ; P<0.001)$, and more likely to be in stage IB (5.8 vs. $5.7 \% ; P<0.001)$ and stage IC (46.0 vs. $26.8 \%$; $P<0.001)$. Compared with non-chemotherapy groups, grade 1 cases were less among the chemotherapy groups $(52.9$ vs. $68.3 \% ; P<0.001)$ and there were more grade 2 cases $(47.1$ vs. $31.7 \% ; P<0.001)$. There was a larger number of patients that had serous cystadenocarcinoma in the chemotherapy groups (33.5 vs. $27.4 \%$; $P=$ 0.001). To eliminate the heterogeneity and imbalance between groups, the present study performed propensity score matching and a logistic regression analysis. The results demonstrated that the two groups both had an equal number of patients, and all clinical factors were well balanced without significant differences, indicating the potential covariates between groups were greatly decreased (Table 2).
Association between chemotherapy and survival

The present study analyzed the association between chemotherapy and 5-year OS for stages IA-IIA. There were no statistically significant differences between the chemotherapy and non-chemotherapy groups (stage IA: 46.5 vs. $53.7 \% ; P=0.110$; stage IB: 49.0 vs.

Table 3 Association of chemotherapy with 5-year overall survival

\begin{tabular}{llll}
\hline Stage & $\begin{array}{l}\text { Chemotherapy- } \\
(n=925)\end{array}$ & $\begin{array}{l}\text { Chemotherapy+ } \\
(n=925)\end{array}$ & $P$-value \\
\hline IA & $53.7 \%$ & $46.5 \%$ & 0.110 \\
IB & $49.1 \%$ & $49.0 \%$ & 0.059 \\
IC & $48.1 \%$ & $46.1 \%$ & 0.750 \\
IIA & $37.2 \%$ & $39.0 \%$ & 0.249 \\
\hline \multicolumn{2}{l}{$\boldsymbol{P}<.05$ was considered to indicate a statistically significant difference }
\end{tabular}


$49.1 \% ; P=0.059 ;$ stage IC: 46.1 vs. $48.1 \% ; P=0.750$; stage IIA: 39.0 vs. $37.2 \% ; P=0.249$ ). Patients with early-stage disease could not benefit from chemotherapy to prolong their 5-year OS (Table 3 and Fig. 2).

\section{Univariate analysis of clinical factors with survival}

The present study performed a univariate analysis of the matched population in order to investigate the prognostic effects of the clinical factors. No significant differences were observed between the chemotherapy and non-chemotherapy groups for 5-year OS $(P=0.245)$. Older age was a risk factor for 5 -year OS $(P<0.001)$. Tumors $>10 \mathrm{~cm}$ in size had lower 5 -year OS $(P=0.014)$. Furthermore, 5-year OS of endometrioid carcinoma was higher than serous cystadenocarcinoma $(P<0.001$; Table 4 and Fig. 3$)$.

\section{Cox proportional hazards model}

The cox proportional hazards model is often used in medical research to investigate the association between survival time of patients and one or more predictive variables. The Kaplan-Meier method and log-rank tests describe survival according to one factor under investigation, but to not include the impact of any others. In addition, they are available only when the predictive variables are categorical, and do not easily work for quantitative predictors, such as age. Given these issues, an alternative method is the cox proportional hazards regression analysis, which works for both quantitative predictive variables and categorical variables. Furthermore, the cox regression model extends survival analysis methods to simultaneously assess the effects of several risk factors on survival time.

In order to investigate how clinical factors jointly impact on survival, the present study took all the factors associated with survival into a multivariate cox regression analysis. The results are presented in Table 5. The analysis revealed that elderly patients (age, $\geq 65$ years) had a higher risk and worse prognosis
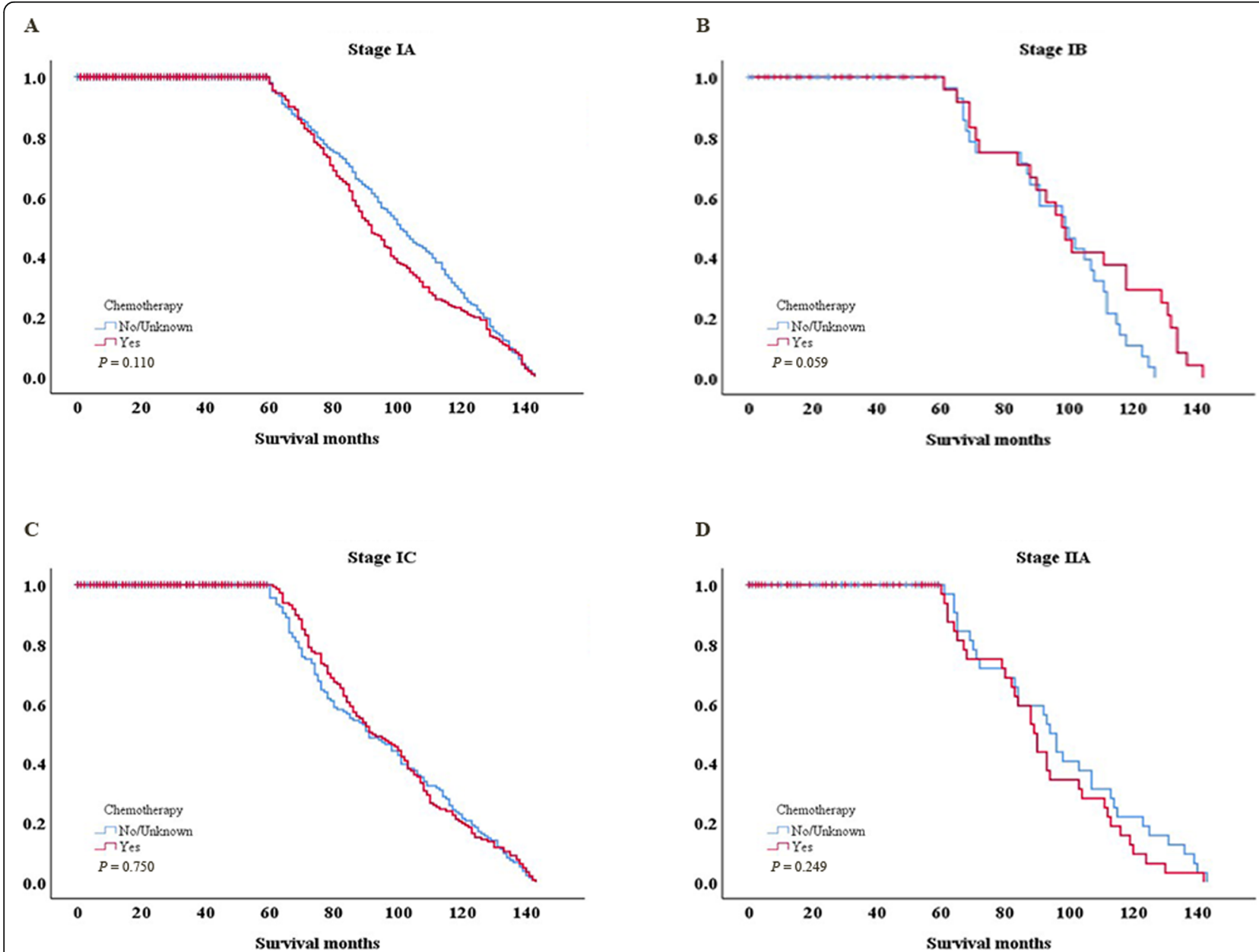

D

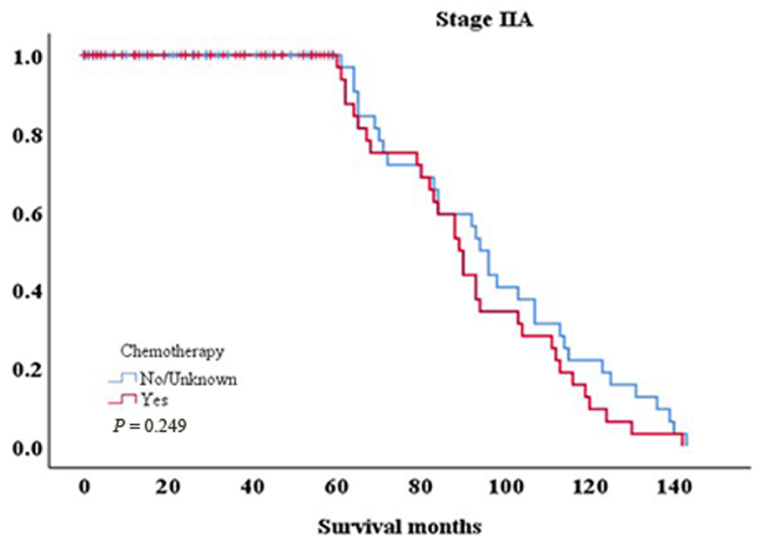

Fig. 2 Kaplan-Meier survival curves for (a) stage IA, (b) stage IB, (c) stage IC and (d) stage IIA drawing on the basis of Table 3. $P<0.05$ was considered to indicate a statistically significant difference 
Table 4 Univariate analysis of clinical factors with 5-year OS

\begin{tabular}{|c|c|c|c|}
\hline Characteristics & No. & 5-year OS, \% & $P$-value \\
\hline Chemotherapy & & & 0.245 \\
\hline No/Unknown & 925 & 50.2 & \\
\hline Yes & 925 & 45.8 & \\
\hline Age, year & & & $<0.001$ \\
\hline$\leq 45$ & 342 & 51.5 & \\
\hline $45-65$ & 1007 & 49.3 & \\
\hline$>65$ & 501 & 43.1 & \\
\hline Race & & & 0.833 \\
\hline White & 1561 & 48.9 & \\
\hline Non-white & 289 & 43.3 & \\
\hline Stage & & & 0.354 \\
\hline IA & 974 & 50.2 & \\
\hline IB & 106 & 49.1 & \\
\hline IC & 602 & 47.0 & \\
\hline$\| \mathrm{A}$ & 168 & 38.1 & \\
\hline Grade & & & 0.908 \\
\hline 1 & 1176 & 51.2 & \\
\hline 2 & 674 & 42.4 & \\
\hline Laterality & & & 0.163 \\
\hline Right & 790 & 46.7 & \\
\hline Left & 806 & 50.5 & \\
\hline Other/Unknown & 254 & 44.1 & \\
\hline Tumor size, $\mathrm{cm}$ & & & 0.014 \\
\hline$\leq 10$ & 830 & 45.5 & \\
\hline$>10$ & 777 & 44.8 & \\
\hline Unknown & 243 & 66.7 & \\
\hline Histology & & & $<0.001$ \\
\hline Serous & 490 & 38.4 & \\
\hline Endometrioid & 1360 & 51.5 & \\
\hline
\end{tabular}

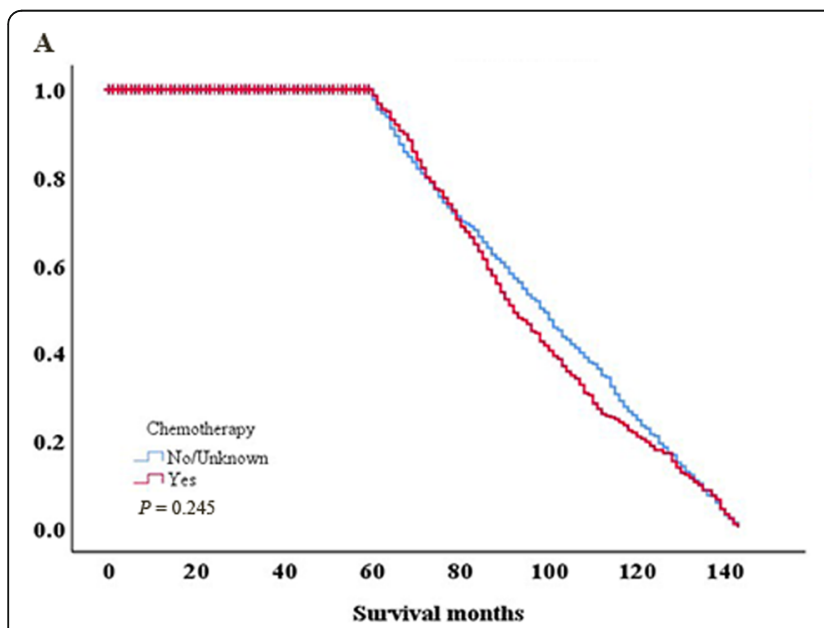

(HR, 1.486; CI, 1.208-1.827; $P<0.001)$. Endometrioid carcinoma was associated with improved 5-year OS (HR, 0.697; CI, 0.584-0.833; $P<0.001$ ). Chemotherapy still had no statistically significant effect on the 5-year OS after excluding the influence of all the confounding factors (HR, 1.092; CI, 0.954-1.249; $P=0.201)$.

\section{Discussion}

The present study was based on a large and unique population-based cohort. The large size of the present study provided the statistical power to investigate the necessity of adjuvant chemotherapy for early-stage serous and endometrioid ovarian cancer. The unique feature of the present study was that each patient included had previously undergone comprehensive staging surgery, which is paramount for survival [16-18]. However, several limitations should be noted, which were inherent to all SEER database analyses. Not all details of the primary surgery could be acquired. The importance of residual disease as a significant prognostic factor for outcome was clearly understood, but accurate surgical data were difficult to obtain for the majority of patients $[7,19]$. Furthermore, the dataset lacked information concerning recurrence free survival and further treatment history affecting prognosis. Therefore, treatment groups may have exhibited additional high-risk features that the authors of the present study were not aware of. To decrease selection bias, propensity score matching was conducted to randomize the dataset and to strengthen causal arguments. Cox proportional-hazards models were recommended by the NCCN guidelines to analyze the associations between variables and survival. Finally, the results from the present study supported recent publications that questioned the

Fig. 3 Kaplan-Meier survival curves for (a) chemotherapy and (b) histology drawing on the basis of Table 4 . $P<0.05$ was considered to indicate a statistically significant difference

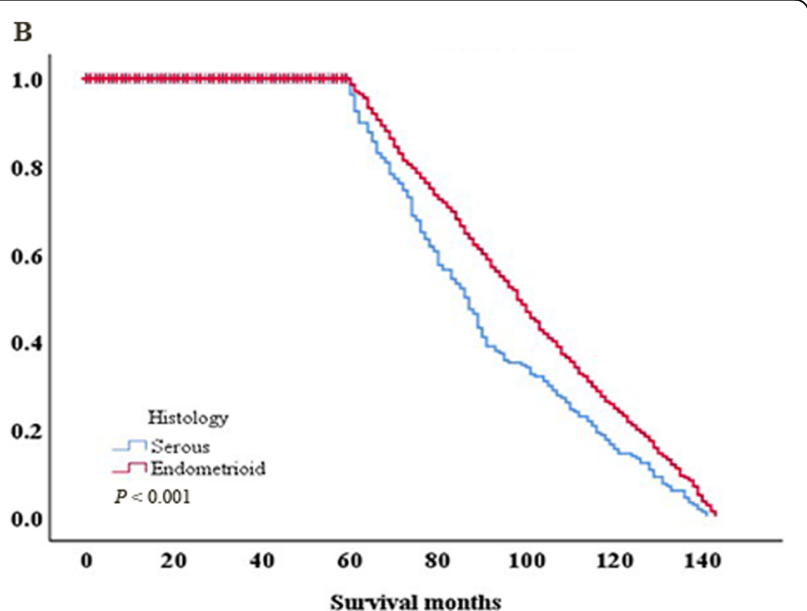


Table 5 Multivariate cox regression analysis for 5-year overall

\begin{tabular}{|c|c|c|}
\hline Characteristics & HR $(95 \% \mathrm{Cl})$ & $P$-value \\
\hline \multicolumn{3}{|l|}{ Chemotherapy } \\
\hline No/Unknown & Ref & \\
\hline Yes & 1.092(0.954-1.249) & 0.201 \\
\hline \multicolumn{3}{|l|}{ Age, years } \\
\hline$\leq 45$ & Ref & \\
\hline $45-65$ & 1.044(0.877-1.244) & 0.627 \\
\hline$>65$ & $1.486(1.208-1.827)$ & $<0.001$ \\
\hline \multicolumn{3}{|l|}{ Race } \\
\hline White & Ref & \\
\hline Non-white & $0.984(0.810-1.195)$ & 0.872 \\
\hline \multicolumn{3}{|l|}{ Stage } \\
\hline IA & Ref & \\
\hline IB & $0.967(0.689-1.359)$ & 0.848 \\
\hline IC & $1.063(0.910-1.241)$ & 0.441 \\
\hline$\| \mathrm{A}$ & $1.128(0.862-1.475)$ & 0.381 \\
\hline \multicolumn{3}{|l|}{ Grade } \\
\hline 1 & Ref & \\
\hline 2 & $0.865(0.743-1.008)$ & 0.063 \\
\hline \multicolumn{3}{|l|}{ Laterality } \\
\hline Right & Ref & \\
\hline Left & $0.984(0.852-1.136)$ & 0.824 \\
\hline Other/Unknown & $1.115(0.862-1.443)$ & 0.407 \\
\hline \multicolumn{3}{|l|}{ Tumor size, cm } \\
\hline$\leq 10$ & Ref & \\
\hline$>10$ & $0.984(0.848-1.141)$ & 0.830 \\
\hline Unknown & $0.760(0.630-0.918)$ & 0.004 \\
\hline \multicolumn{3}{|l|}{ Histology } \\
\hline Serous & Ref & \\
\hline Endometrioid & $0.697(0.584-0.833)$ & $<0.001$ \\
\hline
\end{tabular}

$P<0.05$ was considered to indicate a statistically significant difference. $H R$ hazard ratios, $\mathrm{Cl}$ confidence intervals, Ref reference

value of adjuvant chemotherapy in early-stage epithelial ovarian carcinoma [20-22]. Adjuvant chemotherapy was not necessary for patients with early-stage serous and endometrioid epithelial ovarian cancer after undergoing surgery. An alternative to paclitaxel plus carboplatin has not been identified over the past two decades as the firstline primary chemotherapy for epithelial ovarian cancer [7]. The two canonical drugs decrease the rate of recurrence and mortality, but does not affect long term survival and cannot decrease the eventual likelihood of death from ovarian cancer per se [8]. This is the reasoning for continuing to put patients with early-stage disease through the regimens.

In summary, the present study suggested that patients with early-stage serous and endometrioid ovarian cancer had no need to receive adjuvant chemotherapy when comprehensive staging surgery had been performed. Further investigation is warranted to provide guidance in the management of patients with epithelial ovarian cancer. Evaluation by a gynecological oncologist is strongly recommended for all patients with suspected ovarian cancer. Primary assessment and surgery by a gynecological oncologist can incur a survival advantage. In addition, NCCN suggests that the best form of management for any patient with cancer is in a clinical trial. Thus, clinical trials are urgently required in order to identify patients who may benefit most from adjuvant chemotherapy and to identify the optimal therapeutic strategy.

Acknowledgements

Not applicable.

\section{Authors' contributions}

$\mathrm{SL}$ analyzed the data and wrote the manuscript. ZZ was responsible for direction and proofreading. The author(s) read and approved the final manuscript.

\section{Funding}

The present study was supported by the grant from the Shanghai Municipal Science \& Technology Commission (grant no. 17401930200).

\section{Availability of data and materials}

The datasets analyzed during the present study are available from the corresponding author on reasonable request.

Ethics approval and consent to participate

Not applicable.

\section{Consent for publication}

Yes

\section{Competing interests}

The authors declare that they have no competing interests.

Received: 11 June 2020 Accepted: 28 July 2020

Published online: 09 August 2020

\section{References}

1. Coleman RL, Oza AM, Lorusso D, et al. Rucaparib maintenance treatment for recurrent ovarian carcinoma after response to platinum therapy (ARIEL3): a randomised, double-blind, placebo-controlled, phase 3 trial. Lancet. 2017; 390(10106):1949-61.

2. Ledermann JAP, Embleton ACM, Raja FB, et al. Cediranib in patients with relapsed platinum-sensitive ovarian cancer (ICON6): a randomised, doubleblind, placebo-controlled phase 3 trial. Lancet. 2016;387(10023):1066-74.

3. Parmar MKB, Adams M, Balestrino M, et al. Paclitaxel plus carboplatin versus standard chemotherapy with either single-agent carboplatin or cyclophosphamide, doxorubicin, and cisplatin in women with ovarian cancer: the ICON3 randomised trial. Lancet. 2002;360(9332):505-15.

4. Neilson JP. Adjuvant (post-surgery) chemotherapy for early stage epithelial ovarian Cancer. Obstet Gynecol. 2009;113(5):1157-9.

5. Prendergast EN, Holzapfel M, Mueller JJ, et al. Three versus six cycles of adjuvant platinum-based chemotherapy in early stage clear cell ovarian carcinoma - a multi-institutional cohort. Gynecol Oncol. 2017;144(2):274-8.

6. Zhang X, Wang S, Zhao S, Sun Y, Yang G. Postoperative chemotherapy had no prognostic effect on early-staged young ovarian cancer with unilateral resection. Cancer Med-us. 2018;7(11):5488-96.

7. Agarwal R, Kaye SB. Ovarian cancer: strategies for overcoming resistance to chemotherapy. Nat Rev Cancer. 2003;3(7):502-16.

8. Narod S. Can advanced-stage ovarian cancer be cured? Nat Rev Clin Oncol. 2016;13(4):255-61. 
9. Kudlowitz D, Velastegui A, Musa F, Muggia F. Carboplatin (every 21 days) and divided-dose paclitaxel (days 1, 11): rationale and tolerance in chemotherapy naiive women with high-grade epithelial cancers of Mullerian origin. Cancer Chemoth Pharm. 2018;81(5):847-51.

10. Gornstein E, Schwarz TL. The paradox of paclitaxel neurotoxicity: mechanisms and unanswered questions. Neuropharmacology. 2014;76:175-83.

11. Chen P, Huhtinen K, Kaipio K, et al. Identification of prognostic groups in high-grade serous ovarian Cancer treated with platinum-Taxane chemotherapy. Cancer Res. 2014;75(15):2987-98.

12. Yu Y, Gaillard S, Phillip JM, et al. Inhibition of spleen tyrosine kinase potentiates paclitaxel-induced cytotoxicity in ovarian Cancer cells by stabilizing microtubules. Cancer Cell. 2015;28(1):82-96.

13. Jayson GC, Kohn EC, Kitchener HC, Ledermann JA. Ovarian cancer. Lancet. 2014;384(9951):1376-88.

14. Rizvi I, Celli JP, Evans $\mathrm{CL}$, et al. Synergistic enhancement of carboplatin efficacy with photodynamic therapy in a three-dimensional model for micrometastatic ovarian Cancer. Cancer Res. 2010;70(22):9319-28.

15. Hirst J, Pathak HB, Hyter S, et al. Licofelone enhances the efficacy of paclitaxel in ovarian Cancer by reversing drug resistance and tumor stemlike properties. Cancer Res. 2018;78(15):4370-85.

16. Kozłowska E, Färkkilä A, Vallius T, et al. Mathematical modeling predicts response to chemotherapy and drug combinations in ovarian Cancer. Cancer Res. 2018;78(14):4036-44.

17. Yap TA, Carden CP, Kaye SB. Beyond chemotherapy: targeted therapies in ovarian cancer. Nat Rev Cancer. 2009;9(3):167-81.

18. Dizon DS, Restivo A, Lomme M, et al. For women receiving chemotherapy for clinically apparent early ovarian Cancer, is there a benefit to surgical staging? Am J Clin Oncol. 2008;31(1):39-42.

19. Rustin $G J$, van der Burg ME, Griffin $C L$, et al. Early versus delayed treatment of relapsed ovarian cancer (MRC OV05/EORTC 55955): a randomised trial. Lancet. 2010;376(9747):1155-63.

20. Bell J, Brady MF, Young RC, et al. Randomized phase III trial of three versus six cycles of adjuvant carboplatin and paclitaxel in early stage epithelial ovarian carcinoma: a gynecologic oncology group study. Gynecol Oncol. 2006;102(3):432-9.

21. Sijmons EA, Lankveld MALV, Witteveen PO, Peeters PHM, Koot VCM, Leeuwen JSV. Compliance to clinical guidelines for early-stage epithelial ovarian cancer in relation to patient outcome. Eur J Obstet Gyn R B. 2007; 131(2):203-8.

22. Takada T, Iwase H, litsuka C, et al. Adjuvant chemotherapy for stage I clear cell carcinoma of the ovary. Int J Gynecol Cancer. 2012;22(4):573-8.

\section{Publisher's Note}

Springer Nature remains neutral with regard to jurisdictional claims in published maps and institutional affiliations.

Ready to submit your research? Choose BMC and benefit from:

- fast, convenient online submission

- thorough peer review by experienced researchers in your field

- rapid publication on acceptance

- support for research data, including large and complex data types

- gold Open Access which fosters wider collaboration and increased citations

- maximum visibility for your research: over $100 \mathrm{M}$ website views per year

At $\mathrm{BMC}$, research is always in progress.

Learn more biomedcentral.com/submissions 